\title{
Present-day strain accumulation in the Liupan Shan area, northeastern margin of the Tibetan Plateau by GPS observations
}

\author{
Guojie Meng ${ }^{1, *}$, Xiaoning $\mathrm{Su}^{1}$, Wanzhen $\mathrm{Xu}^{1}$, Chieh-Hung Chen ${ }^{2}$, Kai-Chien Cheng ${ }^{3}$, Strong Wen ${ }^{3}$, \\ Ta-Kang Yeh ${ }^{4}$, Peng Li $^{1}$, Mako Ohzono ${ }^{5}$, and Hiroaki Takahashi ${ }^{5}$ \\ ${ }^{1}$ Key Laboratory of Earthquake Forecasting, Institute of Earthquake Forecasting, China Earthquake Administration, Beijing, \\ China \\ ${ }^{2}$ State Key Laboratory of Geological Processes and Mineral Resources, Institute of Geophysics and Geomatics, China University \\ of Geosciences, Wuhan, China \\ ${ }^{3}$ Department of Earth and Environmental Sciences, National Chung Cheng University, Chiayi, Taiwan \\ ${ }^{4}$ Department of Real Estate \& Built Environment, National Taipei University, New Taipei City, Taiwan \\ ${ }^{5}$ Institute of Seismology and Volcanology, Hokkaido University, Japan
}

\section{Article history:}

Received 28 January 2018

Revised 7 August 2018

Accepted 10 September 2018

Keywords:

Strain accumulation, GPS observation, Earthquake potential, Liupan Shan Fault, Ordos craton, Tibetan Plateau

\section{Citation:}

Meng, G., X. Su, W. Xu, C.-H. Chen, K.-C. Cheng, S. Wen, T.-K. Yeh, P. $\mathrm{Li}, \mathrm{M}$. Ohzono, and H. Takahashi, 2019: Present-day strain accumulation in the Liupan Shan area, northeastern margin of the Tibetan Plateau by GPS observations. Terr. Atmos. Ocean. Sci., 30, 51-62, doi: 10.3319/ TAO.2018.09.10.02

\begin{abstract}
We derived a new GPS site velocity field by integrating the data of ten newly built stations across the Liupan Shan Fault, in the northeastern margin of the Tibetan Plateau and those of pre-existing sites in this area for the period of $1999-2015$. The GPS velocity field in a Eurasian plate-fixed frame shows a clockwise rotation around the Ordos cratonic block. Relative to the Ordos block, GPS sites generally move northeastward. The inferred GPS velocity profile across the Liupan Shan Fault shows that fault-normal velocities decrease from west to east from $5.4 \pm 0.9 \mathrm{~mm} \mathrm{yr}^{-1}$, at the central of the Lanzhou block to $0.1 \pm 0.8 \mathrm{~mm} \mathrm{yr}^{-1}$ at the western Ordos craton. We estimated the locking degree and the slip deficit rate on the Liupan Shan Fault using the tectonic elastic block model. Modeling results show that the Liupan Shan Fault is characteristic of segmentation in terms of locking degree and slip deficit rate. The southern segment has the largest locking degree, with complete locking to the depth of $13-15 \mathrm{~km}$; the locking degree in the central segment is smaller than that of the northern and southern segments. On average, the slip deficit rate at the northern segment is larger than that of the Southern and central segments. We estimate the maximum magnitude of an expected earthquake based on the moment budget since the last large earthquake of M 6.7 in 1921. If the accumulated energy was completely released by a single earthquake, the expected maximum magnitude would be $M_{w} 6.7$. The model prediction suggests a high potential for seismic hazard in the Liupan Shan area.
\end{abstract}

\section{INTRODUCTION}

The Tibetan Plateau has been growing toward the east and northeast, accompanied by extrusion along the left lateral strike-slip faults that slice Tibet's east side. This has been occurring since India collided with Asia 55 million years ago (Tapponnier et al. 2001). In the northeastern margin of the Tibetan Plateau, the NWW-striking Haiyuan Fault is deforming via large-scale left-lateral shearing due to the eastward extrusion of the Tibetan Plateau, forming a compression zone in its southeastern terminus (Deng and Zhang 1989). The compression zone is mainly composed of the

\footnotetext{
* Corresponding author

E-mail: guojiemeng@126.com
}

Madongshan Fold Belt, the Liupan Shan Fault, and the Xiaoguan Shan Fault. The Liupan Shan Fault, located between the Ordos craton in the east and the Lanzhou tectonic block in the west (Loveless and Meade 2011), strikes generally north-northwest (Fig. 1). Connecting with the left-laterally shearing Haiyuan Fault in the north and the Longxian-Baoji Fault in the south, the Liupan Shan Fault is a transition section, undergoing both reverse and left-lateral deformation (Deng et al. 1984, 2019; Burchfiel et al. 1991).

GPS and leveling observations demonstrate that the northeastern margin of the Tibetan Plateau is experiencing significant crustal shortening (Hao et al. 2014a, b). The maximum uplift in the northern part of the Liupan Shan 
Fault occurred close to the fault, but the primary uplift in the southern portion appears $20 \mathrm{~km}$ west of the Liupan Shan Fault (Hao et al. 2014a). These studies show that the Liupan Shan Fault area is accumulating significant strain and the Liupan Shan Fault is strongly locked. However, the details of crustal shortening and strain accumulation in this region are still not very clear.

To characterize strain accumulation and earthquake potential in the Liupan Shan area in the northeastern margin of the Tibetan Plateau, we constructed ten continuously operating GPS stations across the Liupan Shan Fault in 2012 to complement the relatively sparse GPS site coverage here. In this study, we present a new GPS velocity field for the northeastern margin of the Tibetan Plateau by integrating the ten newly built continuous sites, and the sites of the Crustal Movement Observation Network of China (CMONOC), and those of the Continental Tectonic and Environmental Monitoring Network (CTEMN) to identify the spatial distribution of crustal shortening. The locking degree and slip deficit on the Liupan Shan Fault is investigated based on the elastic tectonic block modeling, constrained by the new GPS velocity field. The earthquake potential of the Liupan Shan Fault is estimated using the historical and modern seismic catalogues, and the GPS-derived slip deficit distribution. The estimated maximum magnitude of a potential earthquake is about $M_{w}$ 6.7. This study is beneficial to the seismic hazard assessment in the northeastern margin of the Tibet Plateau.

\section{GPS OBSERVATIONS AND DATA ANALYSIS}

GPS measurements have been conducted in the northeastern margin of the Tibetan Plateau since 1999, when the CMONOC was initiated, and its successor CTEMN commenced in 2010 (Meng et al. 2015). Thirteen CTEMN/ CMONOC continuous GPS stations are distributed within the Lanzhou and Ordos blocks. Additionally, more than 111 CTEMN/CMONOC campaign-mode GPS sites of are located within the study area. Most sites are observed regularly every two years. With the financial support of the project of Study on Strain Accumulation across the Liupan Shan Area, we established 10 continuous GPS stations across the Liupan Shan Fault in 2012 (Fig. 2), with reinforced concrete pillars into bedrock or sediment. All the newly built stations have been operating continuously since early 2013 .

The GPS data are processed using GAMIT/GLOBK software (Herring et al. 2015a, b) to derive time series of the station coordinates in the ITRF2008 reference frame. Regional station coordinates, 11 tropospheric zenith delay parameters per site per day, and phase ambiguities are estimated in each single-day solution. IGS final orbits and IERS Earth Orientation Parameters are used, and elevation-dependent absolute antenna phase center corrections are applied, following the IGS08tables. The daily loosely constrained solutions from our processing are combined with the loosely constrained solutions of $\sim 45$ International GNSS (Global Navigation Satellite Systems) Service (IGS) stations, the data for which are available from the Scripps Orbital and Positioning Analysis Center (SOPAC) (http:// sopac.ucsd.edu). The least squares adjustment vector, the variance-covariance matrix for station positions and orbital parameters estimated for each independent daily solution are then combined with global H-files from the Scripps Institution of Oceanography (SIO). Common parameters in all solutions, such as the satellite orbit, polar motions, and tracking station positions, are solved with loose constraints. In the final step, station positions and velocities are estimated with the QOCA software (Dong et al. 1998) through sequential Kalman filtering, allowing adjustment for global translation and rotation of each daily solution. We impose the reference frame by minimizing the position and velocity deviations of $\sim 45$ IGS core stations with respect to the ITRF2008 (Altamimi et al. 2011) while estimating the orientation, translation, and scale transformation parameters for each day. Random walk perturbations are allowed for the parameters whose errors are correlated with time. The height coordinates and vertical velocities are weighted by a factor of 10 less than the horizontal components. The velocity solution is transformed into a Eurasia-fixed reference frame using the angular velocity parameters of Eurasia with respect to the ITRF2008 (Altamimi et al. 2012). The weighted least squares approach is employed in the fitting of the GPS site position time series with a function of linear, annual and semi-annual components (Bos et al. 2013). The site velocity uncertainties are scaled on a component by component basis according to goodness of fit.

The coseismic displacements due to the $2008 \mathrm{M}_{\mathrm{w}} 7.9$ Wenchuan earthquake, which occurred approximately 450 $\mathrm{km}$ away from the study area, were identified and removed from the GPS position time series. We calculated the coseismic displacements at GPS sites in the Liupan Shan area by the Green Functions of the analytic solutions of Okada (1985) and the finite-fault slip distribution of Shen et al. (2009). Postseismic effects of the Wenchuan earthquake are estimated to be less than $1.0 \mathrm{~mm}$ generally with the rheological lithospheric structure of Diao et al. (2018), an update of Huang et al. (2014). Thus, we did not consider the postseismic deformation for the following analyses. To obtain a reliable velocity field, we utilized only horizontal velocities for continuous and campaign-mode GPS sites. To avoid the effect of non-tectonic signals, we removed data, which falls into the following two categories: (1) a data span less than 3 years for survey-mode sites; (2) the number of surveys was less than 5 times.

Integrating the data of the ten newly built GPS sites and pre-existing GPS sites of CMONOC and CTEMN in the northeastern margin of the Tibetan Plateau, we present a new horizontal field within a stable Eurasian plate-fixed frame (Fig. 3a). The GPS sites within the area of $100-104^{\circ} \mathrm{E}$, 
$35-39^{\circ} \mathrm{N}$, to the northwest of the Ordos block, are characterized by northeastern movement. However, GPS sites west and southwest of Ordos block display a pattern of southeastward movement, indicating a clockwise rotation around the Ordos block (Gan et al. 2007; Meng et al. 2015). At the same time, the estimated GPS velocity field exhibits a consistent west to east decrease in horizontal velocity magnitude from $10.5 \pm 0.8 \mathrm{~mm} \mathrm{yr}^{-1}$ in the area of $100-104^{\circ} \mathrm{E}, 35-39^{\circ} \mathrm{N}$ to $4.9 \mathrm{~mm} \mathrm{yr}^{-1}$ in the western flank of the Ordos block. The consistent variation of movement direction and the west to east decrease of horizontal velocity magnitude can be attributed to the obstruction of the relatively rigid Ordos Bock and the locking effect on the fault patches of the Liupan Shan fault (Meng et al. 2015). We estimate Ordos block angular velocity with an iterative approach (Shen et al. 2005). We first use the velocities of all 19 sites on the Ordos block to estimate the block angular velocity by least squares regress. Then we evaluate the postfit residual $\chi_{n}^{2}$, where $\mathrm{n}$ is the number of site in the block and remove the site with the largest posfit residual and use the remaining site velocities to reestimate the block angular velocity. Subsequently we evaluate the postfit residual $\chi_{n-1}^{2}$, using the $F$-test to evaluate the significance of the outlier by the probability $\mathrm{P}(F)$. The site is removed if the $F$-test exceeds $90 \%$ confidence. The procedure is stopped when $F$-test yields $<90 \%$ confidence. Twelve sites are removed by this procedure. We use the velocities of remaining seven sites to estimate the angular velocity of the Ordos block. The angular rotation is $0.2742 \pm 0.0583^{\circ} \mathrm{myr}^{-1}$ with a pole at $\left(116.1937 \pm 1.9484^{\circ} \mathrm{E}, 44.5454 \pm 1.3864^{\circ} \mathrm{N}\right)$.

We transformed the velocity field with respect to the Eurasian plate-fixed reference frame (Fig. 3a) into the Ordos block-fixed reference frame. The velocity field relative to the Ordos block (Fig. 3b) shows clearly a west to east decrease in horizontal velocity magnitude. The estimated

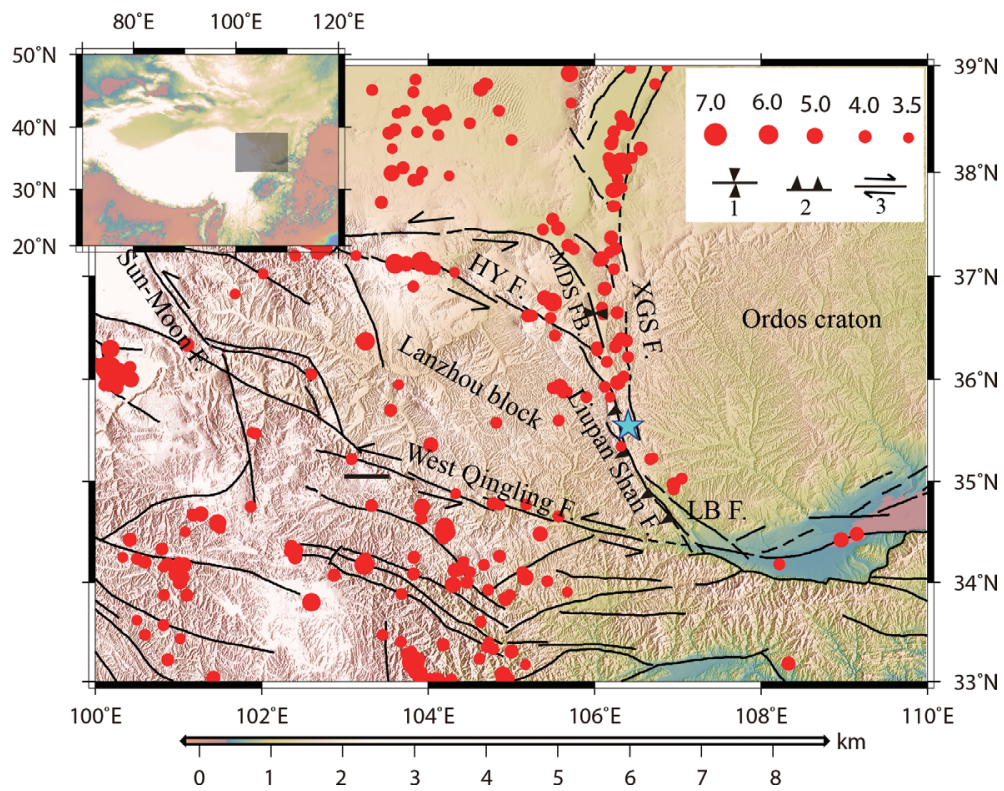

Fig. 1. The seismotectonic framework for the northeastern margin of the Tibetan Plateau. The upper left inset displays the location of this study. The solid lines are Quaternary faults from Deng et al. (2003). Red dots are M $\geq 3.5$ earthquakes from 1965 - 2017 (China Earthquake Networks Center catalogue). The cyan asterisk is the epicenter of 1921 M 6.5 earthquake. Abbreviation are: XGS F., Xiaoguan Shan Fault; HY F., Haiyuan Fault; LB. F., Longxian-Baoji Fault; MDS. F., Madong Shan Fold Belt. 1: Fold belt; 2: thrust; 3: strike slip fault.

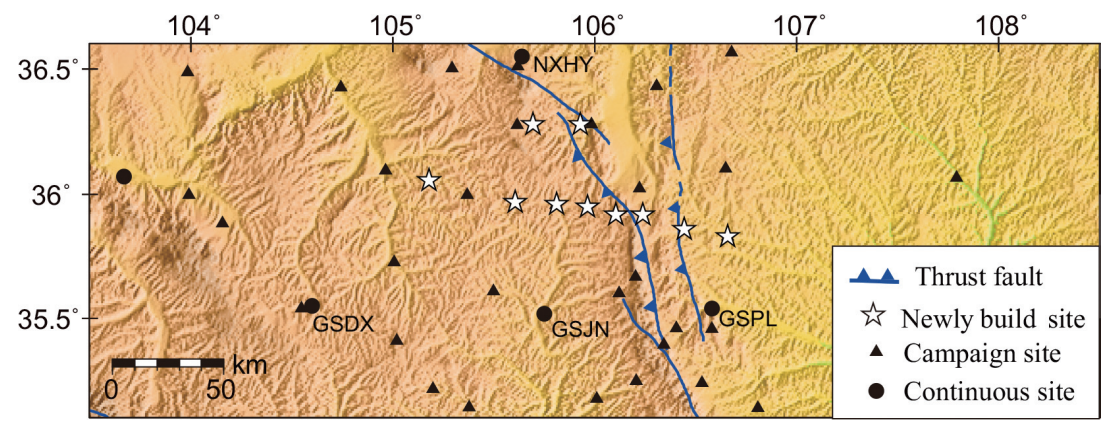

Fig. 2. GPS site array across the Liupan Shan Fault. The 10 newly built sites are continuous sites. 

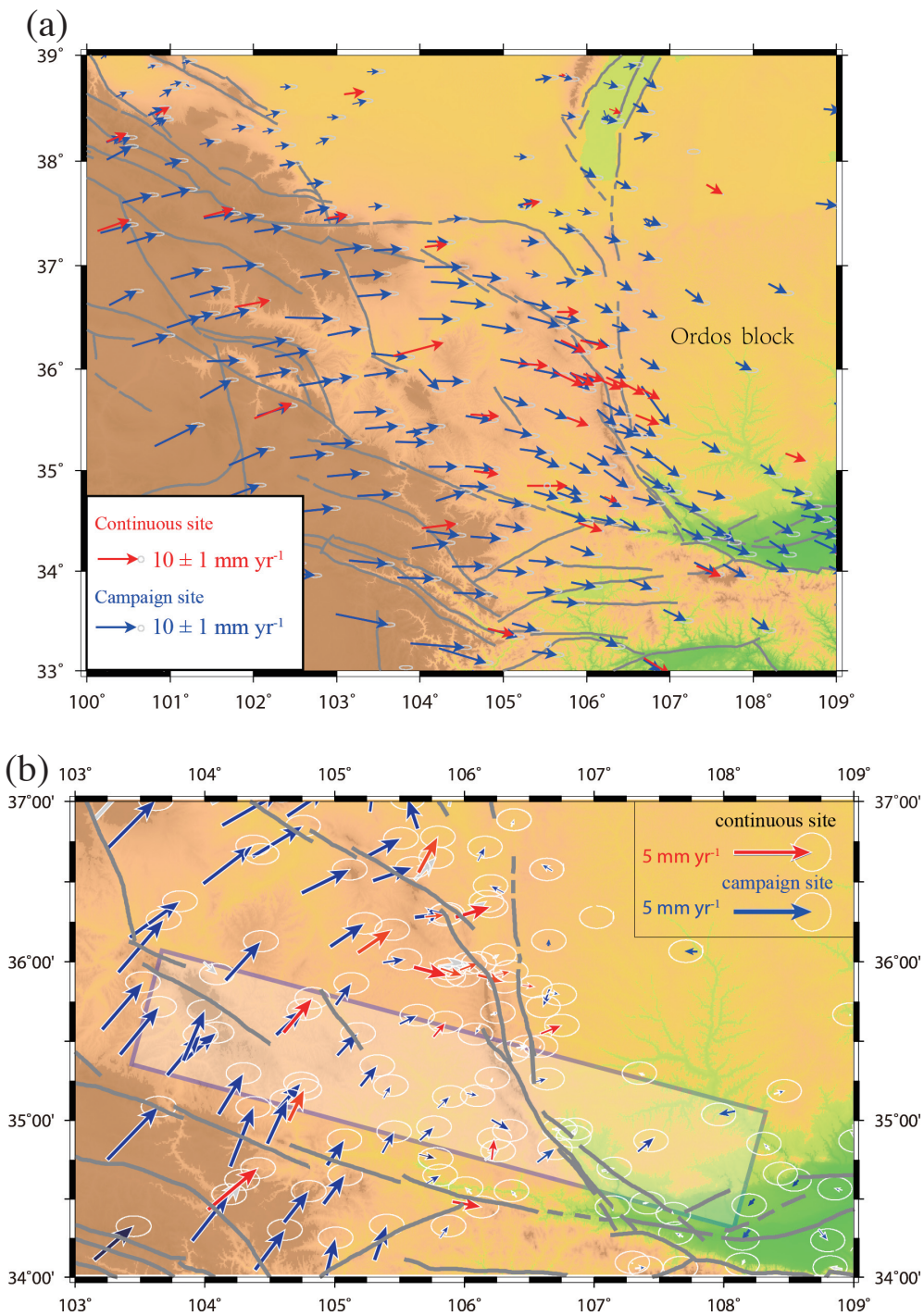

Fig. 3. GPS-derived velocity field relative to (a) Eurasian plate and (b) Ordos block. The rectangle is the profile of Fig. 4.

velocities for most sites near the Liupan Shan Fault are close to zero. To study the horizontal velocity gradient across the Liupan Shan Fault, we made a GPS velocity profile across the fault as shown by the rectangle in Fig. 3b. GPS site velocities within the rectangle are decomposed into faultparallel and fault-normal components, respectively (Fig. 4). It can be seen that a gradient zone is identified from the profile of fault-normal velocity components, which is about $300 \mathrm{~km}$ wide west of the Liupan Shan Fault. No prominent differential motion is identified for the fault-normal and fault-parallel velocity components of GPS sites close to the Liupan Shan Fault, indicating that the Liupan Shan Fault is not very active currently.

\section{GPS VELOCITY INTERPRETATION}

\subsection{Methodology}

GPS horizontal velocities can be modeled as the sum of contributions from tectonic block rotation, elastic deformation from locked faults (backslip) bounding the tectonic blocks, and internal strain within the tectonic blocks (McCaffrey 2013). With respect to the Ordos block, the observed horizontal GPS velocities at the Lanzhou block can be represented as,

$$
\begin{aligned}
V_{k}(\boldsymbol{X})= & {\left[{ }_{R} \boldsymbol{\Omega}_{B} \times \boldsymbol{X}\right]_{k}+\varepsilon_{k k} \Delta \boldsymbol{X}_{k}+\varepsilon_{k l} \Delta \boldsymbol{X}_{l} } \\
& +\sum_{j=1,2} \sum_{j=1, N}\left[-{ }_{R} \boldsymbol{\Omega}_{B} \times \boldsymbol{Q}_{i}\right]_{j} \phi_{i} G_{j k}\left(\boldsymbol{X}, \boldsymbol{Q}_{i}\right)
\end{aligned}
$$

where $\boldsymbol{X}$ is the GPS site position; $V_{k}(\boldsymbol{X})$ is the horizontal velocity of GPS sites at $\boldsymbol{X}{ }_{R} \boldsymbol{\Omega}_{B}$ is the Euler vector of the tectonic block $B$ with respect to the specified reference tectonic block $R ; k$ is the index of GPS velocity components; $\varepsilon$ is the horizontal strain tensor and $\Delta \boldsymbol{X}$ is the differential position vector between the specified reference point for strain tensor and the GPS site. $N$ is the number of nodes on the fault; 
(a)

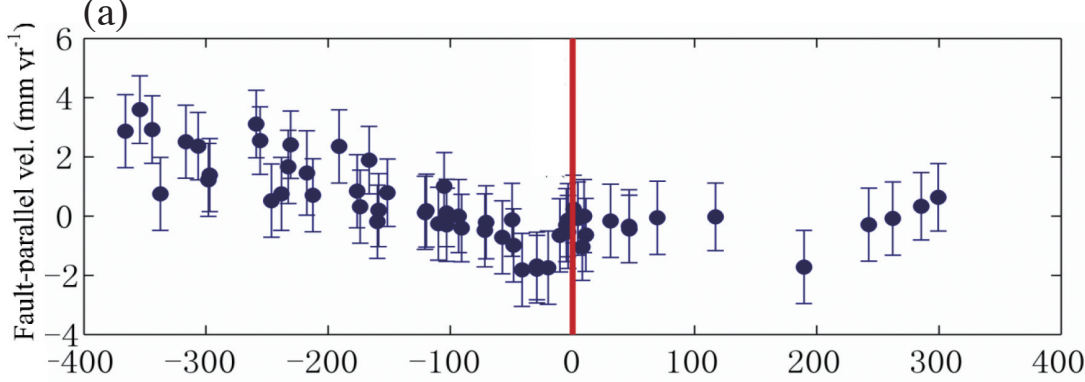

(b)

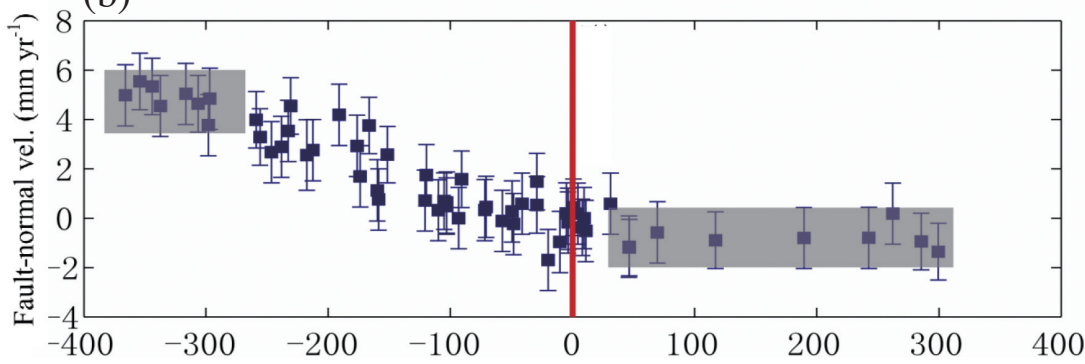

Fig. 4. GPS site velocities along the cross-section shown as in Fig. 3. Upper and lower are the fault-parallel and fault-normal velocity components with $2 \sigma$ error bars. The red lines represents Liupan Shan Fault.

$\boldsymbol{Q}_{i}$ is the position of the $i$ th node; $\phi_{i}$ is the locking rate of the $i$ th node; $\boldsymbol{G}_{i k}\left(\boldsymbol{X}, \boldsymbol{Q}_{i}\right)$ is the Green Functions which represent the velocity component in the direction $k$ of the GPS site at position $\boldsymbol{X}$ due to a unit slip in direction $j$ (along the strike direction or along dip direction) of the node at position $i$.

The DEFNODE program developed by McCaffrey (2013) is employed in the modeling. A hybrid algorithm is used to solve the parameters of the cost function: first, a grid search approach is implemented to obtain initial values of all unknown parameters, and then the stimulated annealing algorithm is used to determine the optimal parameters, including the Euler vector, internal strain tensors of the tectonic blocks, and the slip deficit rates.

The locking degree of the fault can be represented as

$\varphi=1-\frac{V}{V_{0}}=\frac{V_{d}}{V_{0}}$

where $V$ is the estimated slip rate of the fault, $V_{0}$ is the estimate from the relative motion of the adjoining tectonic blocks, $V_{d}$ is the slip deficit rate $\left(V_{0}-V\right)$, and $V_{0}$ is the value calculated from the relative motion of the adjacent tectonic blocks. The locking rate $\varphi$ is generally in the range of 0 and 1 . When $\varphi=0$ the fault is fully creeping and when $\varphi$ $=1$ it is completely locked (McCaffrey 2005). Values of $\varphi$ between 0 and 1 indicate that some parts of the fault creep and some parts do not (McCaffrey 2005).

In this study, the locking rate is allowed to decrease monotonically with depth in the modeling. The goodness of fit is based on the reduced $\chi^{2}$ statistic expressed as (Mc-
Caffrey 2005):

$\chi_{n}^{2}=\left[(N-P)^{-1} \sum_{i=1}^{N} q_{i}\right]$

where $N$ is the number of observed data; $P$ is the number of free parameters; $(N-P)$ is the number of degrees of freedom; and $q$ is a misfit function. For a single GPS velocity with east and north components $V_{e}$ and $V_{n}$,

$q=\boldsymbol{R}^{T} \boldsymbol{C}^{-1} \boldsymbol{R}$

where $\boldsymbol{R}$ is the matrix of velocity residuals; $T$ represents the transpose of the matrix; and $\boldsymbol{C}$ is the EW and NS velocity covariance matrix (McCaffrey 2005).

\subsection{Model Setup and Resolution Test}

The Lanzhou tectonic block and the Ordos cratonic block are two primary tectonic units in the northeastern margin of the Tibetan Plateau (Loveless and Meade 2011). The Ordos cratonic block is the western part of the North China craton, and it is relatively stable compared with the Lanzhou tectonic block (Zhao et al. 2005, 2007). Therefore, the Ordos block is specified as the reference block in this modeling.

The Liupan Shan Fault can be divided into three segments from north to south, based on previous geological and geophysical studies (e.g., Xiang et al. 1998a; Zhang et al. 2004, 2006). The three segments have different geometric parameters as shown by Table 1. A cross-sectional view 
Table 1. Geometric parameters of three segments of Liupan Shan Fault.

\begin{tabular}{ccccc}
\hline Segment & Spatial spanning & Length $(\mathbf{k m})$ & Strike $\left(^{\circ}\right)$ & Dip $\left({ }^{\circ}\right)$ \\
\hline North & Caojiake-Kaicheng & 25 & 330 & $60-70$ \\
Middle & Kaicheng-Xiangshuidian & 35 & 350 & $40-60$ \\
South & Xiangshuidian-Sanzhuangzi & 30 & 340 & $50-70$ \\
\hline
\end{tabular}

of the Liupan Shan Fault shown by Fig. 5 gives the geometric parameters versus depth, modified by the study of seismic wide-angle reflection and refraction sounding ( $\mathrm{Li}$ et al. 2017). The strike direction of the Liupan Shan Fault is $330^{\circ} \mathrm{N}$ for all three segments. In the upper part from the surface to $25 \mathrm{~km}$ in depth, the dip angle is $70^{\circ}$; in the deeper portion below $25 \mathrm{~km}$, the dip angle decreases to $50^{\circ}$. The bottom of the fault model is assumed to be less than $35 \mathrm{~km}$, considering that most $\mathrm{M} \geq 4.0$ earthquakes registered by China Earthquake Networks Center (CENC) are less than $35 \mathrm{~km}$ in depth. To be conservative, we take the lower depth of the fault model to be $40 \mathrm{~km}$. This can also be confirmed by the Moho depth of this region obtained by seismic receiver function inversion and active source sounding (Zeng and Sun 1995; Tong et al. 2007; Li et al. 2014).

The checkerboard approach (Humphreys and Clayton 1988; Jiang et al. 2015) is employed to test the dislocation model resolution. We discretize the Liupan Shan Fault model into $9 \times 5$ subfaults along strike and downdip directions, respectively, each subfault with a size of $10 \times$ $10 \mathrm{~km}^{2}$ (Fig. 6a). In the synthetic model, we set the locked and stable sliding patches alternately in space. We forward calculate the theoretical velocities at each GPS site, based on the analytical solutions of Okada (1985), and then perform an inversion, with a hybrid algorithm encompassing a grid search, and the simulated annealing optimization to calculate locking rates to test how the input model can be recovered. Multiple tests show that generally the shallower patches have higher resolution than those in lower portion, and the locking rate of patches in the central segment of the fault model can be well recovered (Fig. 6b). This indicates that the newly established 10 continuous GPS stations play a significant role in enhancing the model resolution. For several patches that are not well recovered, we merge them with adjoining patches into a single larger patch to ensure that all the patches can be recovered correctly (Fig. 7).

\section{MODELING RESULTS}

\subsection{Model Parameter Setting}

Referring to the above resolution test, we divide the fault model into 6 layers, with layers at $0,5,12,24,36$, and $43 \mathrm{~km}$ in depth, respectively (Fig. 8) and allow the bottom edge of the fault model to slip freely. Several patches are merged into a larger single patch on the upper five lay- ers to secure a good resolution, as guided by the resolution tests. The upper two layers have a dip angle of $70^{\circ}$, and the lower three layers have a dip angle of $50^{\circ}$. The locking degrees of patches are allowed to decrease monotonously downwards. During the optimization procedure, the $F$-test statistical method is taken to exclude GPS sites with statistically anomalous postfit residuals. A smoothing factor is employed to balance the model roughness and the postfit residual. The hybrid algorithm including a grid search and a simulated annealing optimization is used to identify the optimal smoothing factor and the model parameters.

\subsection{Modeling Results}

As shown by Fig. 9, postfit data residual $\chi^{2}$ decreases monotonously with the increase of smoothing factor. If the smoothing factor $\lambda$ is zero, it means that the locking rate is the same along the strike direction of the fault model, only varying along the dip direction. In this case, $\chi^{2}$ is 2.407 . This indicates that if the locking rate is constrained to vary only along the dip direction, it cannot resolve the locking rate variation along the strike direction. When $\lambda$ increases beyond $0.6, \chi^{2}$ gradually decreases to 1.6 or so. Thus, the lower bound of the smoothing factor $\lambda$ should be 0.6 . Lower bound here means the smoothing factor $\lambda$ beneath which the rms misfit begins to rise steeply (Fig. 9). To have a good balance of the model roughness and postfit data residual, we take the smoothing factor of 0.6 to obtain the optimal model parameters. It should be noted that the smoothing factor $\lambda$ here is the maximum variation of locking rates within one degree in space along the strike direction of the fault model.

Figure 10 shows the optimal slip deficit rate of the Liupan Shan Fault model. It can be seen that the slip deficit rates are heterogeneous on the fault model. Generally, the locking rates are higher in the upper zone than those in the lower zone. For the shallow zone, the fully locking depth is at $\sim 6 \mathrm{~km}$ in the northwest and at $13-15 \mathrm{~km}$ in the southeast. The central segment has the smallest slip deficit rates, with full locking depth at $2 \mathrm{~km}$. The zone beneath $40 \mathrm{~km}$ along down-dip direction experiences free sliding everywhere. Overall, the slip deficit rates are in the range of $0-2.5 \mathrm{~mm} \mathrm{yr}^{-1}$. The estimated slip deficit rates (Table 2) show that the maximum slip deficit rate of $1.25 \mathrm{~mm} \mathrm{yr}^{-1}$ is in the southern segment. Following that is the northern segment, where the slip deficit rate is $1.16 \mathrm{~mm} \mathrm{yr}^{-1}$. The central segment has the smallest 


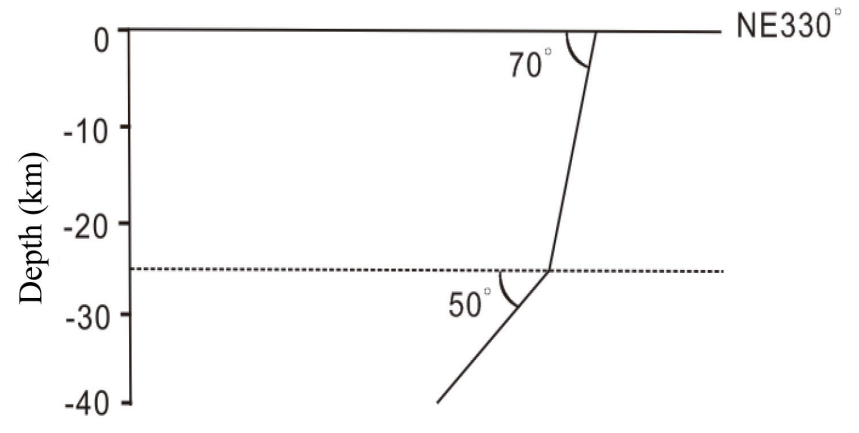

Fig. 5. Cross-sectional view of the Liupan Shan Fault model.

(a)

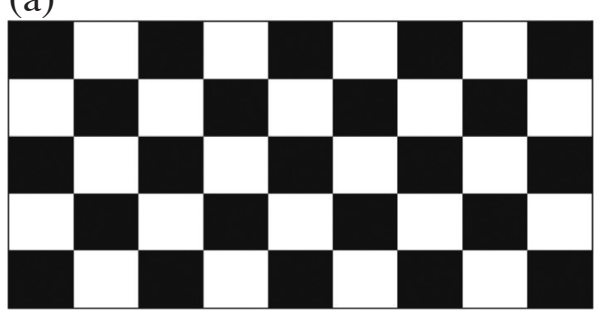

(b)

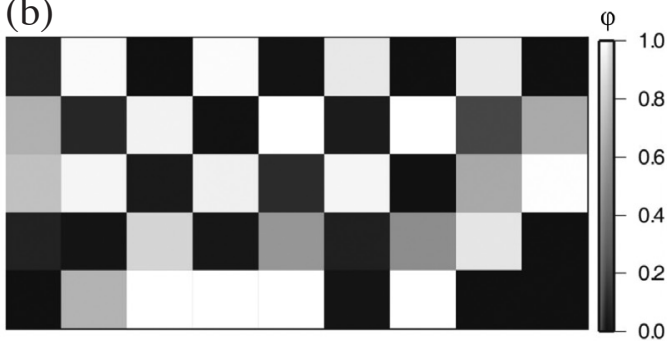

Fig. 6. Fault model resolution check with the Checkerboard approach. (a) Synthetic model; (b) Recovered locking rate. $\varphi$ is the locking rate.

(a)

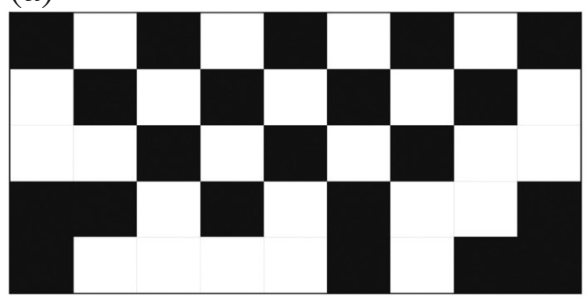

(b)

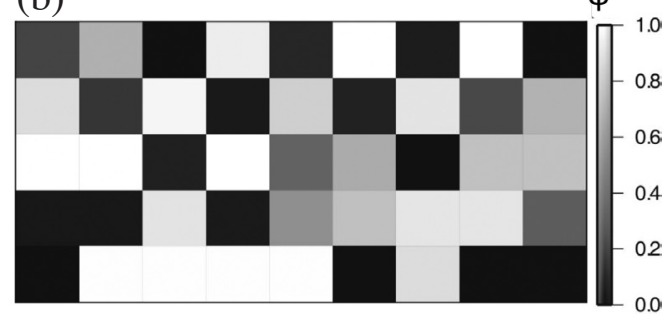

Fig. 7. Liupan Shan Fault model resolution test with partial patches merged. (a) Synthetic locking rate model; (b) Recovered result. $\Phi$ represents locking rate.

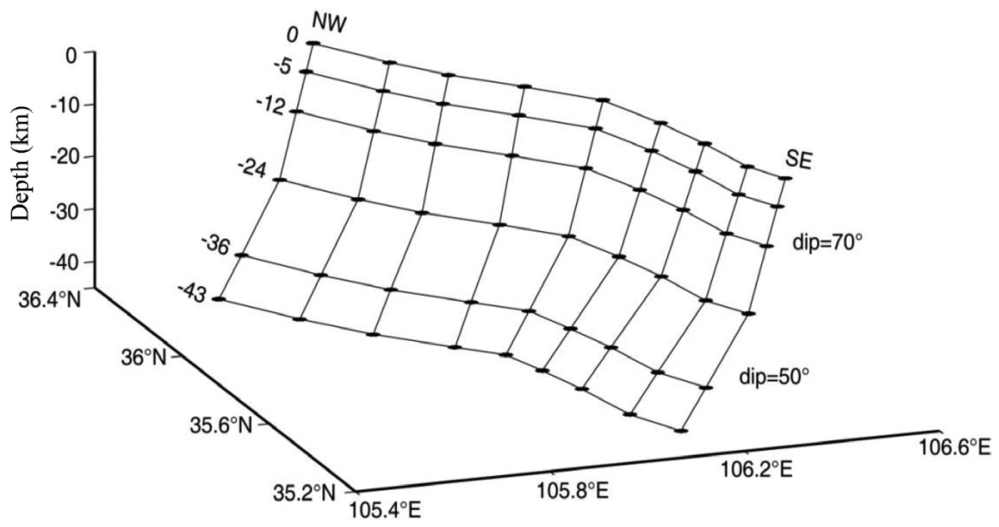

Fig. 8. Configuration of the Liupan Shan Fault model in the inversion for locking and slip deficit rates. 


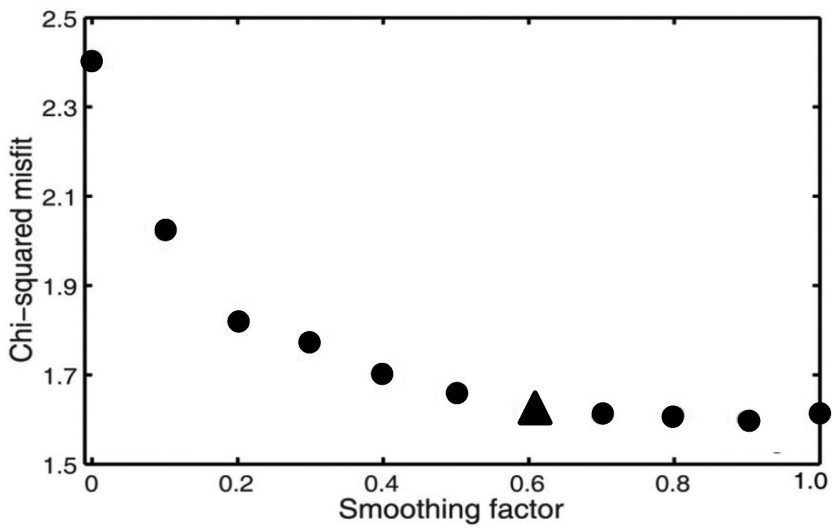

Fig. 9. Postfit data residuals with smoothing factors. The triangle represents the preferred smoothing value.

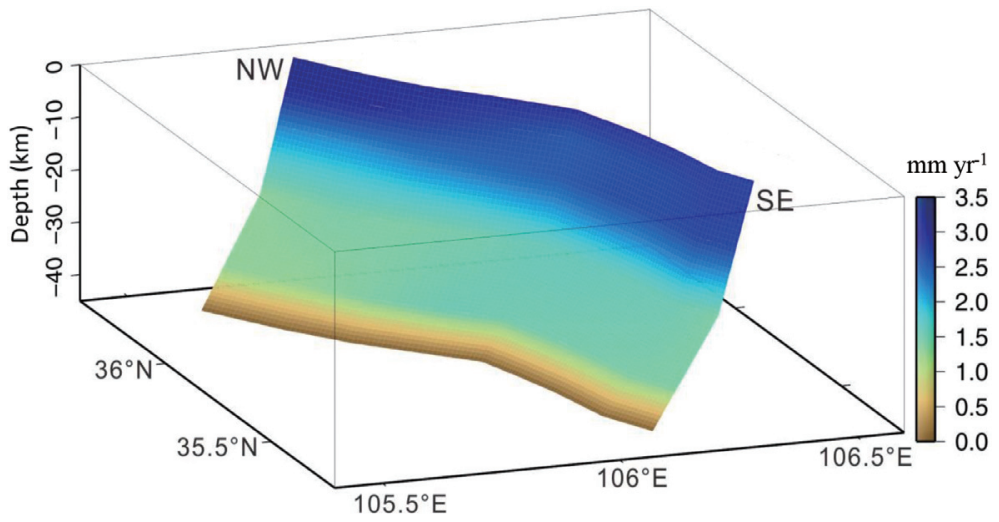

Fig. 10. Three-dimensional view of slip deficit rates on the Liupan Shan Fault.

Table 2. Average slip deficit rates of different segments of the Liupan Shan Fault.

\begin{tabular}{c|ccc}
\hline \multirow{2}{*}{ Depth (km) } & \multicolumn{3}{|c}{ Average slip deficit rate $\left(\mathbf{m m ~ y r}^{-1}\right)$} \\
\cline { 2 - 4 } & Northern segment & Central segment & Southern segment \\
\hline $0-24$ & 1.57 & 1.25 & 1.45 \\
$24-40$ & 0.75 & 0.45 & 1.05 \\
$40-43$ & 0.00 & 0.00 & 0.00 \\
$0-43$ & 1.16 & 0.85 & 1.25 \\
\hline
\end{tabular}

average slip deficit rate at $0.85 \mathrm{~mm} \mathrm{yr}^{-1}$. The shallow zone 0 - $24 \mathrm{~km}$ deep has larger slip deficit rates than those in the deep zone of $24-40 \mathrm{~km}$ for all segments. For the northern segment, the zone at the depth of $0-24 \mathrm{~km}$ has an average slip deficit rate of $1.57 \mathrm{~mm} \mathrm{yr}^{-1}$, two times larger than the slip deficit rate of $0.75 \mathrm{~mm} \mathrm{yr}^{-1}$ of deep zone at $24-40 \mathrm{~km}$. For the southern segment the zone $0-24 \mathrm{~km}$ deep has an average slip deficit rate of $1.45 \mathrm{~mm} \mathrm{yr}^{-1}$, slightly larger than that of deep zone of $24-40 \mathrm{~km}$. For the central segment, the shallow zone has an average slip deficit rate of $1.25 \mathrm{~mm} \mathrm{yr}^{-1}$, more than 2 times larger than that in the deep zone. The slip deficit rate distribution suggests that strain is accumulating faster in the southern segment than in the northern segment. In the central segment, crustal strain is accumulating more slowly compared with the northern and southern segments. The locking depth of central segment is very shallow at a depth of $\sim 2 \mathrm{~km}$, implying possible creeping here.

The block model gives an angular velocity of $-0.6498^{\circ}$ $\pm 0.0479^{\circ} \mathrm{Myr}^{-1}$ for the Lanzhou tectonic block with a pole at $\left(106.288^{\circ} \mathrm{E}, 34.305^{\circ} \mathrm{N}\right)$ with respect to the Ordos block, indicating that the Lanzhou block is undergoing clockwise rotation with respect to the stable Ordos block. The internal 
strain tensor of the Lanzhou tectonic block (Table 3) suggest that the Lanzhou block is experiencing prominent compression. The postfit data residuals as shown by Fig. 11 indicate that the residuals are generally smaller than $2 \mathrm{~mm} \mathrm{yr}^{-1}$ within the interior of Lanzhou and Ordos blocks. However, several sites have residuals more than $2.5 \mathrm{~mm} \mathrm{yr}^{-1}$, possibly due to the activities of subsidiary tectonic units. Overall, the residuals are random in space, without systemic distribution of large residuals.

\section{DISCUSSIONS}

\subsection{Comparison with Previous Studies}

Previous researchers characterized contemporary crustal motion in the northeastern margin of the Tibetan Plateau using small amounts of geodetic data (e.g., Zhang et al. 2004; Gan et al. 2007; Hao et al. 2014a, b; Meng et al. 2015). Crustal shortening was identified in a zone about $300 \mathrm{~km}$ wide west of the Liupan Shan Fault, but horizontal deformation was found to be insignificant close to the Liupan Shan Fault (Hao et al. 2014b). Based on the data of spirit leveling routes across the northern and southern parts of the Liupan Shan Fault, Hao et al. (2014a) claimed that the vertical uplift of the Liupan Shan Fault differs for the northern and southern segments. The largest uplift of the northern segment is close to the fault; the maximum vertical motion of the southern segment appears $20 \mathrm{~km}$ west of the Liupan Shan Fault (Hao et al. 2014a). The differential vertical motion suggests that the southern segment has a higher locking degree than the northern segment. The geomorphological terraces and sample dating reveal that the Quaternary uplift of the Liupan Shan Fault is $0.9 \mathrm{~mm} \mathrm{yr}^{-1}$, with a left-lateral horizontal slip rate at $1-3 \mathrm{~mm} \mathrm{yr}^{-1}$ for the northern part (Xiang et al. 1998a). This geomorphological study shows that the activity of the southern part of the Liupan Shan Fault is smaller, indicative of a higher locking degree. The numerical modeling in this study shows that the Liupan Shan Fault is currently strongly locked, without significant motion over the entire fault, consistent with previous geodetic study (Hao et al. 2014a). On the other hand, the geodetically inferred movement of the Liupan Shan is roughly consistent with late-Holocene motion, documented by geological study (Xiang et al. 1998b), suggestive of an inherited mode of slow strain accumulation in the Liupan Shan area.

\subsection{Limitation of the Elastic Block Model}

Several tectonic blocks are distributed in the northeastern margin of the Tibetan Plateau, including the Lanzhou, Ordos Plateau, Gonghe Nanshan, West Qinling blocks, which are bounded by major Holocene-late Quaternary faults (Deng et al. 2003; Loveless and Meade 2011). Multiple subsidiary faults are distributed within each of the tectonic blocks. To characterize the first-order deformation in the Liupan Shan area in the northeastern margin of the Tibetan Plateau, we simplified the tectonic units in this area in configuring the block model, including the Lanzhou and Ordos blocks and the Liupan Shan Fault. The GPS sites on the Ordos block used in this study are largely located in the western area of this block, thus their velocities are primarily composed of contributions from the motion of the Ordos block and the activity of the Liupan Shan Fault. The Ordos block is a rigid cratonic unit and thus has an insignificant deformation rate. Relative to the Ordos block, the velocities of GPS sites close to east of Liupan Shan Fault are primarily attributed to the activity of this fault. However the velocities of GPS sites at the Lanzhou block could not only include the contribution from the general motion of the Lanzhou block and the activity of the Liupan Shan Fault, but also involve some contribution from the faults bounding the Lanzhou block. The Lanzhou block is bounded by the Haiyuan Fault in the north, West-Qinling Fault in the south and the SunMoon Fault in the west, with all characterized as right-lateral strike-slip faults (Ge et al.2013). The possible effects to GPS site velocities within the Lanzhou block, close to the three faults caused by the three faults are ignored in this modeling. Additionally the subsidiary faults within the Lanzhou block are also ignored in the modeling. The internal strain of the Lanzhou block (Table 3) could be attributed to the factors. About $14 \mathrm{~km}$ east of the Liupan Shan Fault, there is a small blind fault, the Xiaoguan Shan Fault, subparallel to the Liupan Shan Fault (Xiang et al. 1998b). The Quaternary activity of the Xiaoguan Shan Fault is not well characterized geologically due to its less geomorphological features (Xiang et al. 1998b). In this modeling we do not take the Xiaoguan Shan Fault into account, considering the difficulty in separating a small tectonic block between the Liupan Shan Fault and the Xiaoguan Shan Fault, given the sparse spatial coverage of GPS sites between the two faults.

The postfit velocity residual distribution (Fig. 11) shows that the GPS sites within the Lanzhou block, close to the Haiyuan, West-Qinling and Sun-Moon faults have velocity residuals at $\sim 1.5 \mathrm{~mm} \mathrm{yr}^{-1}$, comparable to the uncertainties of observed velocities. No systematic distribution of large residuals is identified for the GPS sites within the Lanzhou block. Additionally, the GPS sites close to the Xiaoguan Shan Fault mostly have small residuals less than $2.0 \mathrm{~mm} \mathrm{yr}{ }^{-1}$, indicating that the activity of the Xiaoguan Shan Fault is insignificant contemporarily. Thus, the simplification in configuring the elastic block model seems to be justified in this study.

\subsection{Implications for Earthquake Hazard Assessment}

The historical earthquake catalogue in the northeastern margin of the Tibetan Plateau has been compiled by China Earthquake Administration (Division of Earthquake Monitoring and Prediction, State Seismological Bureau 1995; 
Table 3. Internal uniform strain rates of Lanzhou block

\begin{tabular}{c|ccc}
\hline \multirow{2}{*}{ Tectonic block } & \multicolumn{3}{|c}{ Strain rate $\left(\mathbf{1 0}^{-9} \mathbf{y r}^{-1}\right)$} \\
\cline { 2 - 4 } & $\boldsymbol{\varepsilon}_{\mathrm{ew}}$ & $\boldsymbol{\varepsilon}_{\mathrm{ns}}$ & $\boldsymbol{\varepsilon}_{\text {en }}$ \\
\hline Lanzhou & $-5.69 \pm 0.77$ & $-6.04 \pm 1.02$ & $-5.84 \pm 0.66$ \\
\hline
\end{tabular}

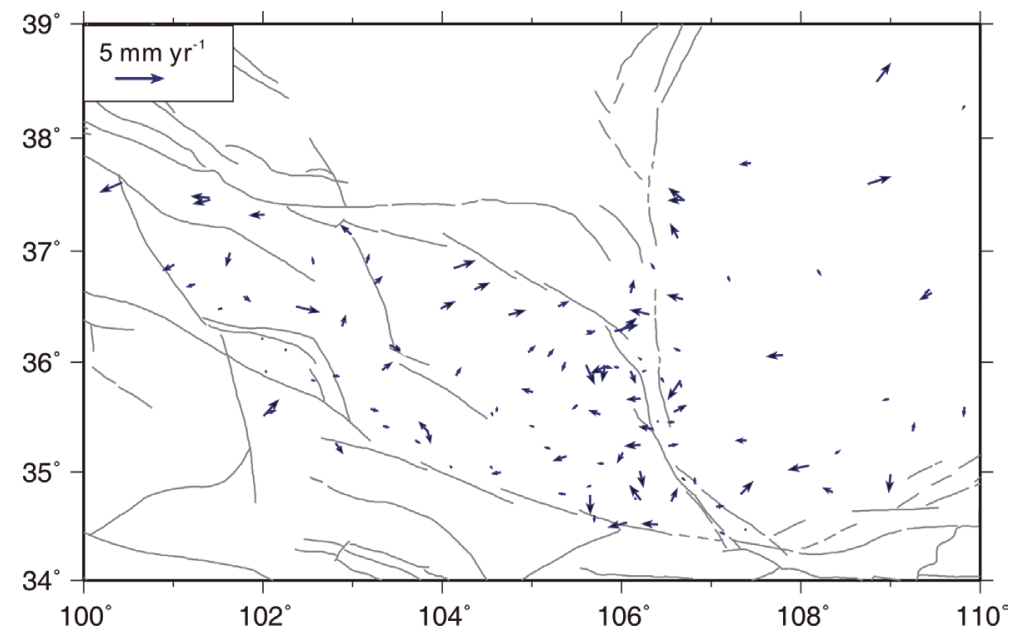

Fig. 11. Postfit data residuals of the elastic block model. The solid lines are active faults.

Division of Earthquake Monitoring and Prediction, State Seismological Bureau 1999). Modern seismic events are well recorded since the setup of seismic monitoring networks in the 1970s in this region. Based on the earthquake catalogue of China Earthquake Data Center (http://data. earthquake.cn/data/), the most recent large earthquake of $\mathrm{M}$ 6.5 occurred close to the Liupan Shan Fault in 1921. Taking this earthquake as the onset of the recent earthquake cycle, we can calculate the accumulated seismic moment since then. The seismic moment rate $\dot{M}$ can be expressed as,

$\dot{M}=\mu s \dot{D} t$

where $\mu$ is the shear modulus or rigidity coefficient of crust; $s$ is the fault area; $\dot{D}$ is the average slip deficit rate; and $t$ is the time span since the last large earthquake. With a shear modulus of $33 \mathrm{GPa}$ (Hamiel et al. 2006; Cochran et al. 2009), the inferred accumulated moment since 1921 is 1.26 $\times 10^{19} \mathrm{Nm}$. Referring to the relationship of earthquake moment and the moment magnitude (Kanamori 1977),

$M_{w}=2 / 3 \log _{10} M_{0}-6.03$

Where $M_{w}$ and $M_{0}$ are moment magnitude and accumulated moment, respectively, since the last earthquake of M 6.5 in 1921, we derive an equivalent magnitude of $M_{w}$ 6.7. This estimate suggests a high potential for seismic hazard in the Liupan Shan area.

\section{CONCLUSIONS}

We report a new GPS site velocity field by integrating the data of the ten newly built continuous stations across the Liupan Shan Fault for the northeastern margin of the Tibetan Plateau and those of pre-existing GPS sites in this area. The GPS velocity field with respect to the stable Eurasian plate exhibits a clockwise rotation. Relative to the Ordos cratonic block, the GPS sites generally move northeastward, reflecting the undergoing northeastward extrusion of the northeastern borderland of the Tibetan Plateau. The GPS velocities of the profile across the Liupan Shan Fault show that fault-normal velocities decrease from west to east from $5.4 \pm 0.9 \mathrm{~mm} \mathrm{yr}^{-1}$ at the central Lanzhou block to $0.1 \pm 0.8 \mathrm{~mm} \mathrm{yr}^{-1}$ at the Western Ordos craton, indicating a crustal shortening within a zone of $\sim 300 \mathrm{~km}$ west of the Liupan Shan Fault. No noticeable GPS site velocity gradient is identified close to the Liupan Shan Fault, suggesting the fault is strongly locked presently.

We invert for the locking degree and slip deficit rate of the Liupan Shan Fault constrained by the GPS velocity field using an elastic tectonic block model. The modeling results show that the Liupan Shan Fault displays segmentation in terms of locking degree and slip deficit distribution. The southern segment has the largest locking degree, with full locking at the depth of $13-15 \mathrm{~km}$; the northern segment has complete locking depth at $\sim 6 \mathrm{~km}$ and the locking degree in the central segment is smaller than that of the northern and southern segments, with complete locking depth at 
$\sim 2 \mathrm{~km}$. On average, the slip deficit rate at the northern segment is larger than that of the southern and central segments, with the largest value of $2.5 \mathrm{~mm} \mathrm{yr}^{-1}$ at the northwesternmost terminus of the fault. We estimate the maximum magnitude of an expected earthquake based on the accumulated moment since the last large earthquake of M 6.5 in 1921, which ruptured the Liupan Shan Fault. If the accumulated energy was completely released by a single earthquake, the expected maximum moment magnitude would be $\mathrm{M}_{\mathrm{w}} 6.7$. The model prediction of the possible earthquake in the future suggests a high potential for large earthquakes in the Liupan Shan area, in the northeastern margin of the Tibetan Plateau, thus further observation of crustal strain accumulation in this area is warranted.

Acknowledgements We thank the guest editor, Xiaodong Song, and two reviewers, Jeff Freymueller and Min-Chien Tsai for their thorough and thoughtful reviews of this manuscript. This work is partially supported by the Natural Science Foundation of China (41874024, 41604007, and 41461164004), International Science \& Technology Cooperation Program of China (2015DFR21100), the Science and Technology innovation fund of Sichuan Earthquake Agency (201804), the MOST (103-2116-M-194-015-MY3 and 106-2116-M-194-004) and the 2017 Beijing Practical Training Program. Chris Hind is thanked for English polishing of the paper. Partial figures were generated using the GMT software (Wessel and Smith 1991).

\section{REFERENCES}

Altamimi, Z., X. Collilieux, and L. Métivier, 2011: ITRF2008: An improved solution of the international terrestrial reference frame. J. Geodesy, 85, 457-473, doi: 10.1007/s00190-011-0444-4. [Link]

Altamimi, Z., L. Métivier, and X. Collilieux, 2012: ITRF2008 plate motion model. J. Geophys. Res., 117, B07402, doi: 10.1029/2011JB008930. [Link]

Bos, M. S., R. M. S. Fernandes, S. D. P. Williams, and L. Bastos, 2013: Fast error analysis of continuous GNSS observations with missing Data. J. Geodesy, 87, 351360, doi: 10.1007/s00190-012-0605-0. [Link]

Burchfiel, B. C., P. Zhang, Y. Wang, W. Zhang, F. Song, Q. Deng, P. Molnar, and L. Royden, 1991: Geology of the Haiyuan fault zone, Ningxia-Hui Autonomous Region, China, and its relation to the evolution of the northeastern margin of the Tibetan Plateau. Tectonics, 10, 1091-1110, doi: 10.1029/90tc02685. [Link]

Cochran, E. S., Y. G. Li, P. M. Shearer, S. Barbot, Y. Fialko, and J. E. Vidale, 2009: Seismic and geodetic evidence for extensive, long-lived fault damage zones. Geology, 37, 315-318, doi: 10.1130/g25306a.1. [Link]

Deng, Q. and W. Q. Zhang, 1989: The Haiyuan strike-slip faulting and its compression tectonics in its terminuses.
Seismol. Geol., 1, 1-14. (in Chinese)

Deng, Q., F. Sung, S. Zhu, M. Li, T. Wang, W. Zhang, B. C. Burchfiel, P. Molnar, and P. Zhang, 1984: Active faulting and tectonics of the Ningxia-Hui Autonomous Region, China. J. Geophys. Res., 89, 4427-4445, doi: 10.1029/jb089ib06p04427. [Link]

Deng, Q., P. Zhang, Y. Ran, X. Yang, W. Min, and Q. Chu, 2003: Basic characteristics of active tectonics of China. Sci.China Ser. D, 46, 356-372, doi: 10.1360/03yd9032. [Link]

Deng, Y., J. Li, X. Song, H. Li, and T. Xu, 2019: The lithospheric-scale deformation in NE Tibet from joint inversion of receiver function and surface wave dispersion. Terr. Atmos. Ocean. Sci., 30, 127-137, doi: 10.3319/ TAO.2019.01.18.03. [Link]

Diao, F., R. Wang, Y. Wang, X. Xiong, and T. R. Walter, 2018: Fault behavior and lower crustal rheology inferred from the first seven years of postseismic GPS data after the 2008 Wenchuan earthquake. Earth Planet. Sci. Lett., 495, 202-212, doi: 10.1016/j. eps1.2018.05.02. [Link]

Division of Earthquake Monitoring and Prediction, 1995: Catalogue of Chinese Historical Strong Earthquake, Seismol. Press, Beijing. (in Chinese)

Division of Earthquake Monitoring and Prediction, 1999: Catalogue of Chinese Modern Earthquakes, Sci. and Technol. Press, Beijing. (in Chinese)

Dong, D., T. A. Herring, and R. W. King, 1998: Estimating regional deformation from a combination of space and terrestrial geodetic data. J. Geodesy, 72, 200-214, doi: 10.1007/s001900050161. [Link]

Gan, W., P. Zhang, Z.-K. Shen, Z. Niu, M. Wang, Y. Wan, D. Zhou, and J. Cheng, 2007: Present-day crustal motion within the Tibetan Plateau inferred from GPS measurements. J. Geophys. Res., 112, doi: 10.1029/2005JB004120. [Link]

Ge, W.-P., M. Wang, Z.-K. Shen, D.-Y. Yuan, and W.-J. Zheng, 2013: Intersiesmic kinematics and defromation patterns on the upper crust of Qaidam-Qilianshan block. Chin. J. Geophys., 56, 2994-3010, doi: 10.6038/ cjg20130913. [Link]

Hamiel, Y., O. Katz, V. Lyakhovsky, Z. Reches, and Y. Fialko, 2006: Stable and unstable damage evolution in rocks with implications to fracturing of granite. Geophys. J. Int., 167, 1005-1016, doi: 10.1111/j.1365246x.2006.03126.x. [Link]

Hao, M., Q. Wang, Z. Shen, D. Cui, L. Ji, Y. Li, and S. Qin, 2014a: Present day crustal vertical movement inferred from precise leveling data in eastern margin of Tibetan Plateau. Tectonophysics, 632, 281-292, doi: 10.1016/j. tecto.2014.06.016. [Link]

Hao, M., S. L. Qin, Y. H. Li, W. P. Wang, and L. Zhou, 2014b: Recent crustal horizontal movement in the northeastern margin of Tibetan Plateau. Geodesy and 
Geodynamics, 34, 99-103. (in Chinese)

Herring, T. A., R. W. King, M. A. Floyd, and S. C. McClusky, 2015a: GAMIT Reference Manual, Massachusetts Institute of Technology, Cambridge.

Herring, T. A., R. W. King, and S. C. McCluskey, 2015b: Introduction to GAMIT/GLOBK, release 10.6, Massachusetts Institute of Technology, Cambridge.

Huang, M. H., R. Bürgmann, and A. M. Freed, 2014: Probing the lithospheric rheology across the eastern margin of the Tibetan Plateau. Earth Planet. Sci. Lett., 396, 88-96, doi: 10.1016/j.eps1.2014.04.003. [Link]

Humphreys, E. and R. W. Clayton, 1988: Adaptation of back projection tomography to seismic travel time problems. J. Geophys. Res., 93, 1073-1085, doi: 10.1029/ jb093ib02p01073. [Link]

Jiang, G., X. Xu, G. Chen, Y. Liu, Y. Fukahata, H. Wang, G. Yu, X. Tan, and C. Xu, 2015: Geodetic imaging of potential seismogenic asperities on the Xianshuihe-Anninghe-Zemuhe fault system, southwest China, with a new 3-D viscoelastic interseismic coupling model. J. Geophys. Res., 120, 1855-1873, doi: 10.1002/2014JB011492. [Link]

Kanamori, H., 1977: The energy release in great earthquakes. J. Geophys. Res., 82, 2981-2987, doi: 10.1029/ jb082i020p02981. [Link]

Li, W.-H., R. Gao, H.-Y. Wang, Y.-K. Li, H.-Q. Li, H.-S. Hou, X.-S. Xiong, X.-Y. Guo, X. Xu, C.-Q. Zou, and H.-D. Liang, 2017: Crustal structure beneath the Liupanshan fault zone and adjacent regions. Chin. J. Geophys., 60, 2265-2278, doi: 10.6038/cjg20170619. (in Chinese) [Link $]$

Li, Y. K., R. Gao, S. X. Mi, Y. T. Yao, J. W. Gao, W. H. Li, and X. S. Xiong, 2014: Crustal velocity structure of Liupan Shan-Ordos Basin, Northeastern margin, Tibetan Plateau. Geology Review, 60, 1147-1157. (in Chinese)

Loveless, J. P. and B. J. Meade, 2011: Partitioning of localized and diffuse deformation in the Tibetan Plateau from joint inversions of geologic and geodetic observations. Earth Planet. Sci. Lett., 303, 11-24, doi: 10.1016/j.epsl.2010.12.014. [Link]

McCaffrey, R., 2005: Block kinematics of the PacificNorth America plate boundary in the southwestern United States from inversion of GPS, seismological, and geologic data. J. Geophys. Res., 110, B0740, doi: 10.1029/2004JB003307. [Link]

McCaffrey, R., 2013: Crustal block rotations and plate coupling. In: Stein, S. and J. T. Freymueller (Eds.), Plate Boundary Zones, Volume 30, American Geophysical Union, 101-122, doi: 10.1029/GD030p0101. [Link]

Meng, G., X. Su, W. Wu, J. Ren, Y. Yang, J. Wu, C. H. Chen, and N. V. Shestakov, 2015: Heterogeneous strain regime in the eastern margin of Tibetan Plateau and its tectonic implications. Earthquake Sci., 28, 1-10, doi: 10.1007/s11589-014-0107-7. [Link]

Okada, Y., 1985: Surface deformation due to shear and tensile faults in a half-space. Bull. Seismol. Soc. Am., 75 , 1135-1154.

Shen, Z. K., J. Lü, M. Wang, and R. Bürgmann, 2005: Contemporary crustal deformation around the southeast borderland of the Tibetan Plateau. J. Geophys. Res., 110, B11409, doi: 10.1029/2004JB003421. [Link]

Shen, Z. K., J. Sun, P. Zhang, Y. Wan, M. Wang, R. Bürgmann, Y. Zeng, W. Gan, H. Liao, and Q. Wang, 2009: Slip maxima at fault junctions and rupturing of barriers during the 2008 Wenchuan earthquake. Nat. Geosci., 2, 718-724, doi: 10.1038/ngeo636. [Link]

Tapponnier, P., F. Roger, B. Meyer, N. Arnaud, G. Wittlinger, and J. Yang, 2001: Oblique Stepwise Rise and Growth of the Tibet Plateau. Science, 294, 1671-1677, doi: 10.1126/science.105978. [Link]

Tong, W. W., L. S. Wang, N. Mi, M. J. Xu, H. Li, D. Y. Yu, C. Li, S. W. Liu, M. Liu, and E. Sandvol, 2007: Crustal and upper mantle structure of Liupan Shan area by receiver Function approach. Sci. China Ser. D, 50, 193-198. (in Chinese)

Wessel, P. and W. H. F. Smith, 1991: Free software helps map and display data. Eos, Trans., $A G U, 72,445-446$, doi: 10.1029/90eo00319. [Link]

Xiang, H., S. M. Guo, B. L. Zhang, W. X. Zhang, I. Ataka, and H. L. He, 1998a: Study on tectonics in the east of Liupan Shan area. Recent Developments in World Seismology, 7, 24-27. (in Chinese)

Xiang, H. F., S. M. Guo, B. L. Zhang, W. X. Zhang, I. Ataka, and H. L. He, 1998b: Late Quaternary activity of reverse fault in eastern Liupan Shan. Seismol. Geol., 4, 34-40. (in Chinese)

Zeng, R. and W. G. Sun, 1995: Moho depth map of China continent. ACTA Seismological SINICA, 17, 322-327. (in Chinese)

Zhang, P. Z., Z. Shen, M. Wang, W. Gan, R. Bürgmann, P. Molnar, Q. Wang, Z. Niu, J. Sun, J. Wu, H. Sun, and $X$. You, 2004: Continuous deformation of the Tibetan Plateau from global positioning system data. Geology, 32, 809-812, doi: 10.1130/g20554.1. [Link]

Zhang, P. Z., D. W. Zheng, G. M. Yin, D. Y. Yuan, G. L. Zhang, C. Y. Lin, and Z. C. Wang, 2006: Discussion regarding to the late Cenozoic expansion and uplift. Quaternary Research, 26, 5-13. (in Chinese)

Zhao, H. G., C. Y. Liu, and F. Wang, 2005: Discussion on the tectonic partitioning in the western Ordos Basin. Earth Frontier, 4, 542-549. (in Chinese)

Zhao, H. G., C. Y. Liu, Y. Yao, F. Wang, and Y. Yin, 2007: The fission track dating evidence of the inconsistent uplift of near western margin of Ordos Basin. Journal of Northwest University Ser. Natural Science, 37, 470474. (in Chinese) 